An analysis of nearshore profile and bar development under large scale erosive and accretive waves

AGUSTIN SANCHEZ-ARCILLA (IAHR Member), Professor, Laboratori d'Enginyeria Maritima (LIM/UPC), Universitat Politècnica de Catalunya (UPC)-Barcelonatech, Barcelona, Spain

Email: agustin.arcilla@upc.edu (author for correspondence)

IVAN CACERES, Researcher, Laboratori d'Enginyeria Maritima (LIM/UPC), Universitat Politècnica de Catalunya (UPC)-Barcelonatech, Barcelona, Spain

Email: i.caceres@upc.edu

Running Head: Nearshore profile development under large scale waves 


\title{
An analysis of nearshore profile and bar development under large scale erosive and accretive waves
}

\begin{abstract}
Typical morphodynamic laboratory tests have been carried out at small scales and without sufficient coverage or resolution. These limitations, applying specially to accretive tests, have prevented obtaining reliable observations and restricted modelling capabilities. Here we present experiments with erosive/accretive waves acting on a large-scale flume bed profile. The paper reports a set of high-quality hydro-morphodynamic data. The analysis is focused on net transport rates and how these patterns change between different accretive conditions. The measured velocity and acceleration skewness are presented and discussed, linking the net transport over the bar to the measured hydrodynamics and sediment concentrations. The resulting profile behaviour is discussed as a function of hydro-morphodynamic settings to facilitate comparisons with other data sets.
\end{abstract}

Keywords: Accretion and erosion; Bar-trough interactions; Mobile bed experiments; Suspended and bed loads; Sediment transport peaks.

\section{Introduction}

Nearshore profile dynamics still present important scientific and engineering challenges (e.g. Baldock, Alsina, Cáceres, Vicinanza, Power, \& Sanchez-Arcilla 2011). Beach profile features and evolution play a key role in coastal engineering projects since most of the morphodynamic impact under a given storm is based on cross-shore processes. In spite of that, profile dynamics have received comparatively less attention than longshore processes and the available knowledge remains partly qualitative and empirical (e.g. Dean \& Dalrymple, 2002) so that many numerical models are not able to predict at a comparable level erosion and accretion processes. In addition most of the research effort has been devoted to erosive processes for very practical reasons, since it is under erosive waves that most of the morphodynamic response occurs. As a consequence, numerical bed evolution models often show a poor performance under accretive conditions (e.g. van Rijn, Tonnon, Sánchez-Arcilla, Cáceres, \& Grüne, 2011), which will not be overcome until a comprehensive and reliable data set for onshore net transport conditions is obtained. In addition accretion is a critical element for natural beach recovery and it needs to be well characterized to carry out an integral impact assessment (Sánchez-Arcilla, Cáceres, \& Grifoll, 2013). 
In cross-shore dynamics, the best established knowledge corresponds to breaker bar features such as their evolution under incoming waves (Roelvink \& Stive, 1989; Guannel, Ozkan-Haller, Haller, \& Kirby, 2007; Sánchez-Arcilla, Cáceres, Van Rijn, \& Grüne, 2011). Recent experimental data show that acceleration skewed oscillatory flows result in a net sediment transport in the direction of the largest acceleration (shoreward) and that its magnitude increases with acceleration skewness (Watanabe \& Sato 2004; van der A, O'Donoghue, \& Ribberink, 2010). Bar formation has been investigated in flume experiments but essentially as an erosive process (Roelvink \& Stive, 1989; Guannel, Ozkan-Haller, Haller, \& Kirby, 2007; Sánchez-Arcilla, Cáceres, Van Rijn, \& Grüne, 2011) in which sediment is suspended at breaking and undertow currents move the solid load towards the offshore. The bar onshore migration has been already linked (Hoefel \& Elgar, 2003; Houser \& Greenwood, 2007) to the velocity and acceleration skewness. Despite some field experiments, focused on the study of onshore sand-bar migrations (van Maanen, Ruiter, Coco, Bryan, \& Ruessink, 2008; Hsu, Elgar, \& Guza, 2006), more work needs to be done in order to get a detailed picture of the velocity and acceleration skewness role on beach profile dynamics in general and breaking bar displacement in particular, specially under accretive conditions and at large scales (e.g. Dubarbier, Catelle, Marieu, \& Ruessink, 2015).

Accretive processes have received some attention lately, but mainly in field studies (e.g. Saye, van der Wal, Pye, \& Blott, 2005; Quartel, Kroon, \& Ruessink, 2008). Just a few laboratory experiments have considered mobile bed accretive conditions, being the more relevant the SANDS (Sánchez-Arcilla, Cáceres, Van Rijn, \& Grüne, 2011; Alsina \& Cáceres, 2011) and SUSCO (Baldock, Alsina, Cáceres, Vicinanza, Power, \& Sanchez-Arcilla 2011; Cáceres \& Alsina, 2016) data sets. The SANDS data set did not include measurements around the bar and therefore only the general profile evolution can be compared with the data here presented. Moreover, during the SUSCO experiments with random accretive waves there was no significant onshore transport due to the mildly accretive conditions and the limited duration of the tests. Some other small scale laboratory accretive experiments, with a mobile bed, can be found at (Atkinson, Shimamoto, Wu, Birrien, \& Baldock, 2015).

The lack of high resolution observations with enough coverage and under controlled conditions has limited the analyses of accretion based on processes. The role of velocity and acceleration in net transport and morphodynamic behaviour has been considered mainly in small scale laboratory experiments (Baldock, Manoonvoravong, \& Kim, 2010) or in a more qualitative manner from field campaigns (Masselink \& Puleo, 2006). As a consequence, the detailed dynamics of accretive beach profiles still require further research to provide a quantitative basis for morphodynamic impact assessment and coastal engineering decisions.

In this paper we shall consider two large scale accretive experiments carried out at the Barcelona CIEM wave flume. The overall aim is to study sediment transport variations under 
different accretive conditions, starting from a previous "natural" (barred) beach configuration. The paper starts with a description of the experiments in Section 2. The accretive net transport is studied in section 3 associated to the breaker bar evolution, while Section 4 analyses the role of skewness and asymmetry at fixed positions during the bar migration. This is followed by a more integrated analysis and intercomparison of the obtained results, which are discussed in Section 5, and by some conclusions and remarks from on-going work in Section 6.

\section{Experimental set-up}

The data here presented were acquired at the Canal d'Investigació i Experimentació Marítima (CIEM) of Universitat Politècnica de Catalunya (UPC), in Barcelona. The CIEM flume is a large-scale wave flume of $100 \mathrm{~m}$ length, $3 \mathrm{~m}$ width and $4.5 \mathrm{~m}$ depth. The experiments considered have a flume bed configuration which starts with a concrete flat part covering a distance of $28 \mathrm{~m}$ from the wavemaker. At this position an initial sandy slope 1/20 is established which extends around $16 \mathrm{~m}$, followed by a sandy horizontal sector that goes along the flume for $4 \mathrm{~m}$ and then comes the 1/15 constant slope up to the end of the profile (black line in Fig. 1b). The water depth at the toe of the wave maker is $2.5 \mathrm{~m}$ for all tested conditions. The granular beach consisted of commercial well-sorted sand with a medium sediment size $\left(\mathrm{d}_{50}\right)$ of $0.25 \mathrm{~mm}$, with a narrow grain size distribution $\left(\mathrm{d}_{10}=0.154\right.$ and $\mathrm{d}_{90}=$ $0.372 \mathrm{~mm}$ ) and a measured settling velocity $(\mathrm{Ws})$ of $0.034 \mathrm{~m} / \mathrm{s}$.

The dimensionless sediment fall velocity number $\Omega=\mathrm{Hs} / \mathrm{WsTp}$, was used to initially predict the Erosive or Accretive character of the tested wave conditions, where Hs and Tp are the significant wave height and peak period of the irregular wave sequences reported on Table 1. Three different wave sequences have been tested to analyse bar dynamics under different transport regimes. The considered wave conditions started from the same 1/15 handmade initial slope. The first test consisted of only erosive waves and it has been used as a "benchmark" data set characterising the transition from a plane slope to a natural barred profile generated by erosive waves mimicking (under controlled and simplified conditions) the process in Nature. During these benchmark tests the erosive time series (Table 2) were repeated during 36 consecutive runs, with a time gap in between each series of 20-30 minutes, in order to accurately recover the profile evolution. The other two data sets that will be considered in this paper (denoted WISE_1 and WISE_2) started again from the 1/15 handmade slope, featuring both a total of 8 erosive wave sequences. For WISE_1 the 8 erosive series run led (Table 2) to the formation of a bar whose main features remained reasonably steady near the end of the experiment. Starting now from this dissipative profile 30 series of accretive waves were executed, providing an accretive data set denoted Ac_1. For the next data set, termed WISE_2, the 1/15 slope was rebuilt and the process started again, 
first with the same 8 erosive time series that were followed by a second run of accretive wave conditions (Ac_2) again featuring 30 consecutive tests in order to obtain the WISE_2 data set. The same as before, after each accretive time series there was a gap of 20-30 minutes to register profile evolution.

All time series have been generated using linear wave theory and a Jonswap spectral density function with $\gamma=3.3$. Each erosive time series had a real time duration of 27 minutes which represents a total of 500 waves. Both accretive tests had the same number of waves (400), and therefore the first accretive time series (Ac_1) is slightly shorter in real time (27 minutes) than the second accretive (Ac_2) series which had a duration of 30 minutes.

The measurement equipment distribution is presented in Fig. 1 and Table 3, where the $\mathrm{x}$-coordinate origin is at the initial shoreline with a still water level of $2.5 \mathrm{~m}$, negative towards the wave paddle (offshore) and positive towards the dry beach (onshore). The water surface elevation was measured by means of resistive wave gauges in the deeper part of the flume (WG), pressure sensors (PPTs) in the surf zone and acoustic displacement sensors (ADSs) in the swash zone. The velocity field was mapped by means of Acoustic Doppler Velocimeters (ADVs), while Optical Backscatter Sensors (OBSs) were used to recover the Suspended Sediment Concentration (hereinafter SSC). The PPTs, ADVs and OBSs were deployed at vertical distances that varied with the $\mathrm{x}$-coordinate, as reported in Table 3.

The bottom profile information was acquired by means of a mechanical bed profiler supplemented in some tests by echo sounder data that register the emerged and submerged profile along a set of flume central lines. Here we present the continuous central line of the flume bed profile, the most reliable one for the general morphodynamic behaviour, as measured by the calibrated mechanical profiler. It consists of a wheel $0.2 \mathrm{~m}$ in diameter on a pivoting arm of length $3 \mathrm{~m}$, which is mounted on a platform that moves at a constant velocity $(0.10 \mathrm{~m} / \mathrm{s})$ above the flume. The computer controlling the platform velocity converts the arm rotation, and therefore the wheel position, into absolute $\mathrm{X}$ and $\mathrm{Z}$ flume bathymetry. More information detailing the complete experimental procedure and equipment deployment can be found on (Cáceres, 2013).

Figure 2 presents on the top panel (Fig. 2a) the bottom evolution for the 8 initial time series during the WISE_1 experiments, while the lower panel (Fig. 2b) presents the standard deviation computed from these profiles; it is during these 8 initial tests, corresponding to the transition from a plane slope to an erosive profile, where most of the sediment transport occurs. The sandy mobile bed ends around $x=-47.5 \mathrm{~m}$ and therefore the red final solid line of the lower panel reports the standard deviation of the measurements over the concrete part of the profile (from -47.5 up to $-51.8 \mathrm{~m}$ ). The standard deviation of the mechanical profiler over a fixed bed has a mean value of $1 \mathrm{~mm}$. The standard deviation of the mechanical profiler measurements over a static sandy bottom has a mean value of $4 \mathrm{~mm}$. This increase in the 
standard deviation on movable bed bottoms is attributable to three causes: repetition of the wheel path over the same line, buoyancy change of the mechanical profiler under a bathymetric variation (mainly at the bar features) and the different level of sand compaction along the profile.

The closure depth for the erosive wave conditions is $-0.96 \mathrm{~m}$, following (Hallermeier, 1978), which provides an estimate for the limit of the active profile that is consistent with the bed profiler observations. This depth is found at an $\mathrm{x}$ around $-15 \mathrm{~m}$. The theoretical maximum run-up during these conditions should be $0.47 \mathrm{~m}$ (following Mase,1989) which represents an $\mathrm{x}$ position of $7.05 \mathrm{~m}$ at the initial profile. The maximum measured run-up is $7.01 \mathrm{~m}$ and corresponds to an average run-up of $6.5 \mathrm{~m}$. To avoid the problem of measuring again and again when there is no sediment transport (in the absence of sediment transport the wheel itself creates a path due to the repeated profiling and the weight of the arm), the net sediment transport computations will be done only over the active part of the profile $(-17>\mathrm{x}$ $>7.3 \mathrm{~m}$ ) as suggested by (Larson \& Krauss, 1994). The limits of the active profile have been selected considering the Hallermeier closure depth, the maximum theoretical run-up but also the measured run-up and standard deviation values for the 8 initial Erosive WISE_1 tests.

The experiments here reported were carried out in two different periods of time and with slightly different transition slopes (part of the profile linking the sandy flat part to the active upper part of the beach) due to the construction technique. Despite this difference, the active part of the profile for the three tested conditions was the same and no effect has been detected on the bar formation and dynamics when comparing the benchmark case and both WISE tests. This is shown in Fig. 3a, presenting the slight difference on the initial part of the $1 / 15$ slope (previous to the active part of the profile located between $\mathrm{x}$ coordinates -30 and $13.5 \mathrm{~m}$ ). It is also illustrated by Fig. 3b, presenting the comparison of bar evolution under the three tested conditions after 8 erosive time series.

Figure 4 demonstrates the repeatability and, thus, comparability of any given measurement for the three considered data sets (benchmark and both WISE experiments). All measurements correspond to the same time gap (from 500 to $600 \mathrm{~s}$ ) within a given time series (6th erosive run in this case). More specifically Figs $4 \mathrm{a}$ and $4 \mathrm{e}$ present surface elevation, $4 \mathrm{~b}$ and $4 \mathrm{f}$ present the velocity, while $4 \mathrm{c}$ and $4 \mathrm{~g}$ show the run-up events. All figures depict in black the measurements for the benchmark test, blue for WISE_1 and red for WISE_2. The central panel in Fig. 4d presents the profile measured evolution and the location of each of the compared measuring points.

The data illustrate the consistency for some of the more robust variables, such as water surface elevation, velocity and run-up. In all cases the data underline the quality of the tests, separated by more than 6 months and with a number of different experiments in between. The good quality of the gathered data supports their combined analysis, cross- 
comparing hydrodynamics (water levels, velocities), sediment transport (near the bed and in suspension) and morphodynamics (bottom evolution).

\section{Erosive conditions (benchmark and WISE experiments)}

Benchmark tests are the yardstick experiments to have a reference for the natural offshore bar (generated from a sloping profile) evolution under continuous erosive conditions. Figure 5a presents the complete profile evolution after $16.2 \mathrm{~h}$ of erosive waves (36 erosive time series in the benchmark tests). Figure $5 \mathrm{~b}$ depicts the bar location (in black) and height (in red) for the same wave trains. The bar location refers to the distance of the bar crest (point of maximum bathymetric height in the bar with respect to the original flume bed) to the original shoreline position (using the $\mathrm{x}$-coordinate system defined in the previous section). The bar height refers to the height of the bar peak relative to the original profile at this same cross-shore location at the beginning of the runs (i.e. relative to the handmade 1/15 slope). The bar evolution (location and height) demonstrates how the expected steady morphodynamic configuration has not been reached and the bar keeps having an offshore movement at the end of the experiment. Despite not reaching a stable configuration after 16.2 hours of erosive time series, the rate of change of the bar at this time frame is rather limited. Between the last two profiles there is a bar offshore displacement of $0.08 \mathrm{~m}$ and there is no gain in bar height (change lower than $1 \mathrm{~cm}$ ).

The cross-shore profile wave height evolution appears in Fig. 6a for the 36 benchmark tests. The main observed wave height changes are related to the bar location and development. The dots represent the mean Hs for each test series, while the red intervals indicate the standard deviation for the 36 series of measurements at each location.

ADV velocity data were processed and spike noise eliminated using the method developed by Goring \& Nikora, 2002. Low quality data, with signal amplitude below $75 \mathrm{~dB}$ and signal to noise ratio below $15 \mathrm{~dB}$, were discarded (considered as $\mathrm{NaN}$ values). The clean signal is treated using a low pass filter with a cut frequency of $3 \mathrm{~Hz}$ and from the resulting signal the peak of velocity maxima (shoreward) and minima (offshoreward) are obtained. The peaks surrounded by $\mathrm{NaN}$ from previous data processing were also discarded, to avoid considering isolated peaks and discontinuous velocity readings. The velocity peaks detected for each time series are then used to compute the velocity and acceleration skewness at each location. All time series which present more than $70 \%$ of $\mathrm{NaN}$ in the treated signal (cleaned and de-spiked time series) have been discarded for any subsequent analysis (these cases are rare within the acquired data sets and represent around $3 \%$ of the measured velocity time series).

The velocity results presented on Fig. 7 correspond to the 8 initial erosive wave sequences. After these 8 erosive series the accretive runs (to be studied in next section) 
started. The analysis here corresponds to the erosive part of the experiments. Figure $7 \mathrm{a}$ presents the measured velocity (positive is onshore) evolution with erosive test number $\left(\mathrm{U}_{\text {mean }}\right.$ solid line with squares, $U_{\text {rms }}$ dashed line with circles and $U_{\min / \max }$ dotted line with pentagrams). Each colour in the plot presents the velocity measurements at a different $\mathrm{x}$ location as reported in the legend of the figure. Figure $7 b$ presents the distribution in space of the corresponding measurements. $U_{\min }$ and $U_{\max }$ (black dots) represent the lower/upper $1 / 3$ of the measured peak velocities, positive/shoreward and negative/offshoreward.

Figure 8 presents the cross-shore distribution of net sediment transport rates $\left(Q_{(x)}\right)$ for the 8 initial erosive time series. These net transport rates are computed using a sediment conservation Exner-type equation (Baldock, Alsina, Cáceres, Vicinanza, Power, \& SanchezArcilla 2011; Alsina, Padilla, \& Cáceres, 2016), along the active part of the profile (x between $-17 \mathrm{~m}$ and $7.3 \mathrm{~m}$ ). They characterise the erosive profile behaviour.

\section{Accretive conditions (WISE_1 and WISE_2 experiments)}

Figure 9 presents the transition from the initial 1/15 handmade slope to a natural barred profile after 8 erosive wave sequences and then the evolution of the bar under 2 different sets of accretive conditions. The plot presents in solid lines the different measured profiles in WISE_1, while the dashed lines represent those measured during WISE_2. Three profiles are plotted for each data set: initial profile in grey, blue for the profile after the 8 erosive sequences and red for the final profile after the 30 accretive tests. The comparison of measured bed profiles after 8 erosive series, blue lines on Fig. 9, report a maximum difference between both experiments of $0.04 \mathrm{~m}$, found at $\mathrm{x}=-13.03 \mathrm{~m}$ (at the offshore side of the bar).

This is about half of the maximum difference found between both initial profiles (grey lines), which was $0.07 \mathrm{~m}$ at $\mathrm{x}=0.01 \mathrm{~m}$ (at the still water shoreline). The reason for that initial inaccuracy is found in the practical problems to achieve a similar degree of sediment compaction during the handmade profile construction. The shoreline is an area with high initial mobility, where more sediment has to be "redistributed" after the tests when reshaping the profile; because of that it is in this sector of the flume that the sediment should be properly and consistently compacted to achieve repeatability and to avoid the profiler wheel sinking more than desired and, thus, reporting an unrealistic low profile. The greatest error source during the profile recovery is due to compaction differences in the initial $1 / 15$ handmade slope, particularly at the emerged part of the profile near the shoreline (the profiler becomes lighter when submerged and heavier during the emerged part of the profile).

The red lines in Fig. 9 present the bar displacement towards the shoreline induced by the different tested accretive conditions. The general behaviour of both accretive experiments is consistent with the tested conditions: Ac_1 waves are less accretive, according to the fall velocity and profile parameter (e.g. Dean, 1973; Dalrymple, 1992), than Ac_2 waves. 
Therefore the bar under Ac_1 shows a more limited advance towards the shoreline, quantified in position and volume in Fig. 10. Both conditions produce a shoreward bar movement but there are important differences in the transient states of such displacement that will be here further studied. These differences are more relevant when considering the bar sequential evolution due to bar interaction and control over the hydrodynamics of wave breaking that, in turn, control sediment transport and bar dynamics. Figure 10 presents the evolution of some of the main bar features for both accretive tests: a) for Ac_1 and b) for Ac_2. The figure depicts the bar location (horizontal distance from the peak of the bar to the initial shoreline position, left y axis in black) and bar height (vertical distance of the peak of the bar to the initial 1/15 slope at this same $\mathrm{x}$ location, right $\mathrm{y}$ axis in red). The dashed green lines present the point at which the erosive conditions end and start the accretive wave sequences. The morphological behaviour of the bar under both accretive conditions is significantly different: Ac_1 tends to "physically" drive the bar towards the shore, while Ac_2 tends to smooth out the bar (bar height for tests 15-18 is nearly negligible with a maximum of $7 \mathrm{~cm}$ ) and use the resulting sand to fill the trough gap where later on a reformed bar will appear, showing a net shoreward displacement of the bar crest. This behaviour is summarized by the bar height and location on Fig. 10b, but it can also be observed on the profile evolution presented on Fig. 11.

Figure 11 illustrates the observed profile evolution and the location of the ADV/OBS pairs collocated at morphodynamically relevant locations $(x=-10.85 \mathrm{~m},-8.65 \mathrm{~m},-6.4 \mathrm{~m}$ and $2 \mathrm{~m}$ ). The horizontal and vertical positions of this equipment appear on Table 3 and are also used in next section to study the velocity field and suspended sediment concentrations when analysing the differences that produce both types of bar migration.

As it was done for the erosive sequences, the net sediment transport rates are computed from a comparison of profile evolving volumes (during the whole set of test series available) and using a sediment conservation Exner equation along the active part of the profile beach ( $\mathrm{x}$ between $-17 \mathrm{~m}$ and $7.3 \mathrm{~m}$ ). Figure $12 \mathrm{c}$ and $12 \mathrm{~d}$ present the net sediment transport calculated from the 30 tested accretive conditions (Ac_1 and Ac_2 respectively). The obtained bed evolution results indicate a total (combining bed and suspended loads) shoreward net transport for Ac_2 tests of about $3.06 \times 10^{-5} \mathrm{~m}^{2} \mathrm{~s}^{-1}$, while the total net transport for Ac_1 is in the offshore direction, of about $-2.4 \times 10^{-6} \mathrm{~m}^{2} \mathrm{~s}^{-1}$. These transport estimates are derived from the observed eroded/accreted volumes in the profiler data and correspond, thus, to an average for the 30 runs available at each accretive condition.

\section{Discussion and Results}

The differential behaviour observed for accretive profile evolution in these large scale experiments indicates a delicate (thus non robust) balance affecting nearshore hydrodynamics 
and the splitting between bed and suspended loads, which can only be tenuously inferred from the available observations. Although only the total net transport can be calculated from the bed evolution data, the measured velocity profiles and the imposed Rouse concentration (based on the optical backscatter recordings) show how a small (about $25 \%$ ) variation of the dimensionless fall velocity (from Ac_1 to Ac_2) results in markedly different transient bar dynamics, although both conditions produce a shoreward bar displacement. Ac_1 series produce a negative (offshoreward) total net transport while Ac_2 series produce a positive (onshore ward) total net transport.

To start the inter comparison we shall focus on the initial accretive stages, where the profile geometries are similar and the observed differences are controlled mainly by the different generated waves. Table 4 presents the $\mathrm{x}$-directed cross-shore mean velocities and SSC measured along the profile during the 5 initial time series for both Ac_1 and Ac_2 conditions. The measured velocities (including the wave orbital and averaged components) are always above the wave boundary layer at an average height of $0.11 \mathrm{~m}$ over the sandy bottom. To compute suspended sediment transport the mean velocity and suspended sediment concentration have been extrapolated to a vertical profile, although the original registers appear in the table.

The suspended sediment profile has been obtained from a Rouse concentration distribution, while the velocity profile has been adjusted to a parabolic distribution from the bottom to the trough of the waves. Despite this being a rough estimation of both profiles, inevitable considering the low resolution in the vertical of the performed measurements, the authors have validated this extrapolation with previous data sets where more measurement points were available at each vertical, obtaining a reasonable support for the employed distributions in terms of the resulting suspended sediment fluxes. The differences in SSC in some verticals that show similar undertow is due to the non-instantaneous character of suspended load, reflecting the lag between hydrodynamics and morphodynamics associated to the variety of processes responsible for the suspended transport: entrainment, re-suspension, settling...These processes have a "memory "that varies with the main acting hydrodynamic driver (short or long waves, bed shear stress, etc.). The more important peaks in SSC appear in all cases near the bar and in the swash zone, reflecting the strong turbulent interactions produced by the up and down rush.

Based on these arguments, we have compared suspended fluxes (load) under both accretive tested conditions. Figures $13 \mathrm{a}$ and $13 \mathrm{~b}$ present the total net sediment transport computed by means of the Exner equation as previously explained; Figures $13 \mathrm{c}$ and $13 \mathrm{~d}$ depict the depth averaged computation of the suspended sediment flux and Figs $13 \mathrm{c}$ and $13 \mathrm{f}$ 
show the bottom evolution during the considered wave sequences (five initial accretive conditions for Ac_1 and Ac_2).

Results from Ac_1 (Fig. 13c) show suspended sediment fluxes which are more than 1 order of magnitude larger than the values computed for Ac_2 (Fig. 13d), being the point of maximum transport the area in the lee side of the bar.

Figure 14 presents the wave breaking fraction $(\mathrm{Qb})$ calculated from the measured wave height decay using two state of the art formulations. The results correspond to the two tested conditions with similar bed profiles (last erosive and first accretive geometries) so that bathymetric change can be neglected as a source of discrepancy for the computed $\mathrm{Qb}$. The threshold to detect a wave has been set at $0.02 \mathrm{~m}$ (all oscillations lower than this value are not considered as a wave) and the number of recorded waves along the flat part of the profile is $99 \%$ of generated waves for erosive conditions while it is $95 \%$ of generated waves for both accretive conditions. Over and behind the bar crest the computed $\mathrm{Qb}$ values following two different formulations (Battjes \& Janssen, 1978; Baldock, Holmes, Bunker, \& Van Weert, 1998) were higher for Ac_1 (Fig. 14a) than for Ac_2 (Fig. 14b). More specifically Qb on top of the bar is three times larger for Ac_1 than for Ac_2 and approximately five times the value at the bar trough.

The SSC signals obtained from the OBS under the different tested conditions indicate the number of events able to produce relevant suspended sediment transport. For the last five erosive time series the percentage of time where the sediment is over the threshold of $2.5 \mathrm{~g} / 1$ is $24 \%$ and $45 \%$ of the tested time at the locations with $\mathrm{x}=-10.7 \mathrm{~m}$ and $-8.7 \mathrm{~m}$ respectively. These percentages drop to about $5 \%$ and $10 \%$ for mildly accretive waves (Ac_1) and around $1 \%$ for stronger accretive waves (Ac_2) at both locations. The net transport at the beginning of the bar (between $\mathrm{x}=-17 \mathrm{~m}$ to $-8 \mathrm{~m}$ ) is rather similar for Ac_1 and Ac_2 and the prevailing hydrodynamics in terms of velocity moments are also similar. However the bar moves towards the onshore in Ac_1 due to the suspended load that feeds it from the shore side; this suspended transport is of about $800 \mathrm{~kg} / \mathrm{m} 2$ for Ac_1. In Ac_2 the bar trough is filled up by the bed load transport, more important in relative terms for this case due to the smaller levels of turbulent energy. The suspended transport in Ac_2 is of order $30 \mathrm{~kg} / \mathrm{m} 2$, one order of magnitude smaller than for Ac_1. This produces a disappearance of the bar until a new one is generated further onshore, confirming that also the waves in Ac_2 are of accretive character.

Table 4 confirms that mean SSC values around the bar are lower for Ac_2 than the corresponding measurements for Ac_1. The observations of SSC and resuspension events must be considered together with the information provided by Fig. 14, which indicates a wave breaking fraction (over the bar) that for Ac_2 is half of the Qb value computed for Ac_1. This means that for Ac_2 there are less breaking waves (less turbulence maintaining the suspended load) and thus the observed lower SSC. The undertow for Ac_2 over the bar and in the trough 
is also half of the undertow values recorded for Ac_1 experiments. This explains why the suspended sediment fluxes in Ac_2 tests (Fig. 13) are clearly smaller than for Ac_1. This difference is more evident in the ADV-OBS data corresponding to the trough of the bar, where most of the wave breaking is effective in re-suspending sediment and the computations of suspended sediment fluxes are an order of magnitude larger for Ac_1 than for Ac_2. The result is that for Ac_2 the bed load is a larger fraction of the total transport which is, thus, more intense towards the onshore, explaining the migration of the bar towards the shore.

Considering that the skewness in velocity $(\mathrm{R})$ and acceleration $(\beta)$ are linked to the bed load transport (e.g. Gonzalez-Rodriguez \& Madsen, 2007; Silva, Abreu, van der A, Sancho, Ruessink, Van der Werf, \& Ribberink, 2011) we have obtained both parameters (R and $\beta$ ) to assess any possible sediment flux changes induced by differences in the hydrodynamics of the tested conditions (Ac_1 and Ac_2). Following Doering \& Bowen, 1995 both parameters can be computed using simple statistics from the measured velocity series (Eq. 1). Alternatively both parameters can be calculated (Ribberink \& Al-Salem, 1994) from the maximum and minimum free stream velocities and accelerations (Eq. 2).

$$
\begin{array}{rr}
R=\frac{\overline{U^{3}}}{U_{r m s}^{3}} & \beta=\frac{\overline{a^{3}}}{a_{r m s}^{3}} \\
R=\frac{U_{\text {max }}}{U_{\text {max }}-U_{\text {min }}} & \beta=\frac{a_{\text {max }}}{a_{\text {max }}-a_{\text {min }}}
\end{array}
$$

Both methods, the first one using a statistical framework and the second one a wave by wave approach, have been employed here to analyse the data at different cross-shore locations. Both formulations provide similar results indicating enough consistency to attempt explaining the main bar morphodynamic features in terms of these hydrodynamic parameters, although the profile evolution will be also conditioned by many other variables (long wave energy, degree of soil compaction, transient hydro-morphodynamic events not well resolved by the data, etc.). The effect of different initial geometries (perturbations often inevitable when building a profile section) may also lead to different evolutions (Atkinson, Shimamoto, Wu, Birrien, \& Baldock, 2015). In the cases here presented, however, this has not been observed due to the effort to achieve repeatable initial profiles for both accretive conditions. This has led to repeatable accretive sequences with a high level of consistency.

The summarized hydrodynamics appear in Fig. 15, presenting the skewness and asymmetry computed following Eq. 2 and the different parameters measured in a wave by wave analysis. Both initial accretive tests (empty squares for the first Ac_1 and empty pentagrams for the first Ac_2) are shown. Wave skewness (black symbols) and asymmetry 
(red symbols) indicate the same trend for both tested conditions, as it should be for accretive sequences with similar velocity skewness and asymmetry, although reflecting the different levels of energy and turbulence between both experiments. Ac_1 presents more energetic incident waves and, thus, a stronger undertow and turbulence leading to more offshore directed transport. Ac_2 is characterized by a dominance of the bed load transport, as it corresponds to lower levels of turbulence and undertow; in this case the breaker bar is not fed from the onshore side and bed load tends to fill up the trough leading to the disappearance of the bar and the generation of a new one at a position closer to the shore. The values here presented correspond to the initial tests within each of the accretive experimental sequences (Ac_1 and Ac_2) but there are not any relevant changes when considering a wider set of cases. However, with the start of a divergent bathymetric evolution there begins a different trend in the calculated parameters which would hamper the intercomparison.

The computed net sediment transport, obtained as before from bed profiler data and corresponding to an average estimate for the whole time series within each test, shows values of $2.1010^{-5}$ and $2.5810^{-5} \mathrm{~m} 2 / \mathrm{s}$ for Ac_1 and Ac_2, respectively. These estimates correspond to the bar area and the initial accretive series. To characterize the net transport over the bar, the computation has been repeated from the steady part of the profile $(x=-17 \mathrm{~m})$ up to the minimum level point within the trough, which is located at $\mathrm{x}=-8 \mathrm{~m}$. The net transport flux over the bar under both accretive conditions is rather similar, suggesting a common morphodynamic trend.

In (Dubarbier, Catelle, Marieu, \& Ruessink, 2015) it was concluded that asymmetry tends to produce an onshore sandbar migration together with slow bar growth; skewness induced transport can drive onshore and offshore bar migrations with substantially larger rates. Our experimental data sets do not allow a clear distinction between asymmetry and skewness transports, but the tested conditions suggest that both mechanisms are contributing to drive the bar with similar net transport rates for both tested accretive conditions.

\section{Conclusions}

The relative scarcity of large scale data sets on accretive profile dynamics has limited the advancement of knowledge and predictive models for beach accretion. This has also precluded the incorporation of natural beach recovery (post storm accretion) into morphodynamic assessments and coastal engineering designs. The controlled experiments here presented, carried out at a large scale wave flume, have been used to gain insight into accretive beach processes with a level of accuracy and robustness not commonly available in the literature. 
The sequences of plane slope-dissipative barred profile-reflective concave profile have allowed establishing the repeatability of three different sets of hydraulic tests: the first covering only erosive sequences (benchmark case) and the other two covering the full set of erosive and accretive conditions. The derived hydro-morphodynamic results have been used to analyse the surf and swash zone water and sediment fluxes and the feedbacks between hydro and morphodynamics. For this paper the emphasis has been on the main breaker bar evolution under accretive waves, to explain the differential behaviour until reaching a final configuration depending on commonly employed bulk hydro-morphodynamic parameters.

The computed breaker bar parameters, net transport rates and wave/current moments across the more active part of the mobile bed section show significant differences in the transient profile dynamics, as a function of the relative importance of bed and suspended loads. Even though both accretive conditions present a trend to displace the bar towards the shore, the mildly accretive wave sequences (Ac_1) produce an onshore migration of the bar trough geometry while the more accretive wave conditions (Ac_2) show an onshore directed net sediment pulse that fills up the trough and then creates a new bar onshorewards of the original crest.

The less energetic accretive sequences (Ac_2) produce lower re-suspension events and a smaller intensity (fraction) for the wave breaking over the bar. At the same time these accretive waves present lower undertow and therefore lower offshore directed suspended sediment fluxes that explain why the bar can be destroyed and then reconstructed. The characterization of "accretiveness", however, remains a difficult subject when based on a limited number of parameters as it happens in field or laboratory experiments. This can be illustrated by the dependence of landward transport on relative fall velocity, which presents a bell shape and, thus, does not allow a bijective relationship between fall velocity and accretive transport (Baldock, Alsina, Cáceres, Vicinanza, Power, \& Sanchez-Arcilla 2011; 2016; Atkinson, Shimamoto, Wu, Birrien, \& Baldock, 2015). In spite of these differences the net bar shoreward displacement is similar under both accretive tested conditions, as it should be expected from the similar values of the skewness and asymmetry for Ac_1 and Ac_2 around the bar.

While both accretive conditions feature similar shoreward net transports (associated to bed load), the suspended sediment fluxes are mainly directed towards the offshore and with a higher intensity (particularly in the trough area) under Ac_1 tests. This offshore transport feeds the bar development and contributes to maintaining an active bar form under the mildly accretive wave conditions. The much lower magnitude of this transport under Ac_2 wave sequences results in a partial disappearance of the bar in the intermediate stages of accretive evolution. The bar erosion feeds the trough replenishment and after this a new bar, compatible with the breaking hydrodynamics, is formed at the new breaker location. 
Such differential behaviour may be used in the future to predict, as a function of the initial beach profile and the forecasted wave conditions, when and how a breaker bar is going to evolve. With the present level of information, however, it is not yet possible to model bar morphodynamics as a function of profile settings and prevailing hydrodynamics. With the advance of knowledge from field and laboratory observations it should become feasible to design flexible interventions based on these bar dynamics to maintain a beach profile or to favour natural recovery.

\section{Acknowledgements}

The authors want to acknowledge the discussions within the Hydralab team and the support of the CIEM staff and mainly Q. Sospedra during the flume experiments. Finally the authors want to thank the reviewers for their useful remarks to improve the manuscript.

\section{Funding}

The experimental part of this work was supported by EC research projects HYDRALAB IV (Contract no. 261520) and HYDRALAB+ (Horizon 2020 grant agreement no. 654110). The authors also want to acknowledge the support received from the MINECO-FEDER PlanWave project (CTM2013-45141-R). This paper is within the work for research excellence by Secretaria d'Universitats i Recerca, Department 'Economia i Coneixement, Generalitat de Catalunya (Ref 2014SGR1253).

\section{Notation}

$a=$ observed water acceleration $\left(\mathrm{ms}^{-2}\right)$

$d=$ sediment diameter $(\mathrm{mm})$

$H_{S}=$ significant wave height $(\mathrm{m})$

$\mathrm{R}=$ velocity skewness

$\mathrm{Qb}=$ fraction of breaking waves

$Q x=$ cross-shore net transport per meter of flume width $\left(\mathrm{m}^{2} \mathrm{~s}^{-1}\right)$

$T p=$ peak wave period (s)

$U=$ observed water velocity $\left(\mathrm{m}^{2} \mathrm{~s}^{-1}\right)$

$W s=$ sediment fall velocity $\left(\mathrm{m}^{2} \mathrm{~s}^{-1}\right)$

$X=$ horizontal coordinate along the flume axis (m)

$Z=$ vertical coordinate in the flume $(\mathrm{m})$ 
$\beta=$ acceleration skewness

$\gamma=$ dimensionless spectral width parameter

$\Omega=$ dimensionless sediment fall velocity

\section{References}

Alsina, J.M., Padilla, E. \& Cáceres, I. (2016). Sediment transport and beach profile evolution induced by bi-chromatic wave groups with different group periods. Coastal Engineering, 114, 325-340.

Alsina, J.M., Cáceres, I. (2011). Sediment suspension events in the inner surf and swash zone. Measurements in large-scale and high-energy wave conditions. Coastal Engineering, 58(8), 657-670.

Atkinson, A., Shimamoto, T., Wu, S., Birrien, F. \& Baldock, T. (2015, September). Beach profile evolution under cyclic wave climates. Paper presented at the meeting of Australasian Coasts and Ports Conference 2015: $22^{\text {nd }}$ Australasian Coastal and Ocean Engineering Conference and the $15^{\text {th }}$ Australasian Port and Harbour Conference. Auckland, New Zealand.

Baldock, T.E., Holmes, P., Bunker, S. \& Van Weert, P. (1998). Cross-shore hydrodynamics within an unsaturated surf zone. Coastal Engineering, 34, 173-196.

Baldock, T.E., Manoonvoravong, P. \& Kim S.P. (2010). Sediment transport and beach morphodynamics induces by free waves, bound long waves and wave groups. Costal Engineering, 57, 898-916.

Baldock, T.E., Alsina, J.A., Cáceres, I., Vicinanza, D., Power, H. and Sanchez-Arcilla, A. (2011). Large-scale experiments on beach profile evolution and surf and swash zone sediment transport induced by long waves, wave groups and random waves. Coastal Engineering, 58, 214-227.

Battjes, J.A. \& Janssen, J.P.F.M. (1978, August-September). Energy loss and set-up due to breaking of random waves. Paper presented at the meeting of International Conference on Coastal Engineering, Hamburg, Germany.

Cáceres, I. (2013). Data Storage Report of WISE IV (Erosive + Accretive). Internal report from Canal d'Investigació i Enginyeria Marítima of Universitat Politecnica de Catalunya.

Cáceres, I. \& Alsina, J.M. (2016). Suspended sediment transport and beach dynamics induced by monochromatic conditions, long waves and wave groups. Coastal Engineering, 108, $36-55$.

Dalrymple, R.A. (1992). Prediction of storm/normal beach profiles. Journal of Waterway, Port, Coastal and Ocean Engineering, 118, 193-200. 
Dean, R.G. (1973). Heuristic model of sand transport in the surf zone. Paper presented at the meeting of Conference on Engineering Dynamics in the Surf Zone, Sydney.

Dean, R. G. \& Dalrymple, R.A. (2002). Coastal processes with engineering applications, Cambridge Univ. Press, Cambridge, U.K.

Doering, J.C. \& Bowen, A.J. (1995). Parameterization of orbital velocity asummetries of shoaling and breaking waves using bispectral analysis. Coastal Engineering, 26, 15-33.

Dubarbier, B., Catelle, B., Marieu, V. \& Ruessink, G. (2015). Process-based modeling of cross-shore saandbar behavior. Coastal Engineering, 95, 35-50.

Elfrink, B., Hanes, D.M. \& Ruessink, B.G. (2006). Parameterization and simulation of near bed orbital velocities under irregular waves in shallow water. Coastal Engineering, 53, 915-927.

Goring, D.G. \& Nikora, V.I. (2002). Despiking acoustic doppler velocimeter data. Journal of Hydraulic Engineering, 128(1), 117-126.

Gonzalez-Rodriguez, D. \& Madsen, O.S. (2007). Seabed shear stress and bedload transport due to asymmetric and skewed waves. Coastal Engineering, 54, 914-929.

Guannel, G., Ozkan-Haller, H. T., Haller, M. C. \& Kirby, J. T. (2007, May). Influence of velocity moments on sand bar movement during CROSSTEX. Paper presented at the Sixth International Symposium on Coastal Engineering and Science of Coastal Sediment Processes, New Orleans, Louisiana.

Hallermeier, R.J. (1978, August-September). Uses for a calculated limit depth to beach erosion. Paper presented at the meeting of International Conference on Coastal Engineering, Hamburg, Germany.

Hoefel, F. \& Elgar, S. (2003). Wave induced sediment transport and sand bar migration. Science, 299(5614), 1885-1887.

Houser, C. \& Greenwood, B. (2007). Onshore migration of a swash bar during a storm. Journal of Coastal Research, 23(1), 1-14.

Hsu, T.-J., Elgar, S. \& Guza, R. T. (2006). Wave-induced sediment transport and onshore sandbar migration. Coastal Engineering, 53, 817-824.

Larson, M. \& Kraus, N.C. (1994). Temporal and spatial scales of beach profile change, Duck, North Carolina. Marine Geology, 117, 75-94.

Mase, H. (1989). Random wave run-up height on gently slope. Journal of Waterway, Port, Coastal and Ocean Engineering, 115(5), 649-661.

Masselink, G. \& Puleo, J.A. (2006). Swash-zone morphodynamics. Continental Shelf Research,26(5), 661-680.

Nielsen, P. \& Callaghan, D.P. (2003). Shear stress and sediment transport calculations for sheet flow under waves. Coastal Engineering, 47, 347-354. 
Quartel, S., Kroon, A. \& Ruessink, B.G. (2008). Seasonal accretion and erosion patterns of a microtidal sandy beach. Marine Geology, 250(1-2), 19-33.

Ribberink, J.S. \& Al-Salem, A.A. (1994). Sediment transport in oscillatory boundary layers in cases of rippled beds and sheet flow. Journal of Geophysical Research, 99(C6), 1270712727.

Roelvink, J.A. \& Stive, M.J.F. (1989). Bar-generating cross-shore flow mechanisms on a beach. Journal of Geophysical Research, 94(C4), 4785-4800

Sánchez-Arcilla, A., Cáceres, I. \& Grifoll, M. (2013, July). Observing shoreline fluxes. Implications for swash and surf zone modelling. Paper presented at the meeting of 7th International Conference on Coastal Dynamics. Bordeaux, France.

Sánchez-Arcilla, A., Cáceres, I., Van Rijn, L. \& Grüne, J. (2011). Revisiting mobile bed tests for beach profile dynamics. Coastal Engineering, 58, 583-593.

Saye, S.E., van der Wal, D., Pye, K. \& Blott, S.J. (2005). Beach-dune morphological relationships and erosion/accretion: An investigation at five sites in England and Wales using LIDAR data. Geomorphology, 72(1-4), 128-155.

Silva, P.A., Abreu, T., van der A., D., Sancho, F., Ruessink, B.G., Van der Werf, J. \& Ribberink, J. (2011). Sediment transport in nonlinear skewed oscillatory flows: Transkew experiments. Journal of Hydraulic Research, 49, 72-80.

van der A, D.A., O'Donoghue, T. \& Ribberink, J.S. (2010). Measurements of sheet flow transport in acceleration-skewed oscillatory flow and comparison with practical formulations. Coastal Engineering, 57, 331-342.

van Maanen, B., Ruiter, P.J., Coco, G., Bryan, K.R. \& Ruessink, B.G. (2008). Onshore sandbar migration at Tairua Beach (New Zealand): Numerical simulations and field measurements. Marine Geology, 253, 99-106.

van Rijn, L.C., Tonnon, P.K., Sánchez-Arcilla, A., Cáceres, I. \& Grüne, J. (2011). Scaling laws for beach and dune erosion processes. Coastal Engineering. 58, 623-636.

Watanabe, A. \& Sato, S. (2004). A sheet flow transport formula for asymmetric forwardleaning waves and currents. Paper presented at the meeting of the International Conference on Coastal Engineering, Lisbon, Portugal. 